\title{
Infrared touch technology as a response detector in animal research
}

\author{
RICHARD PISACRETA \\ Ferris State College, Big Rapids, Michigan \\ and \\ MARK RILLING \\ Michigan State University, East Lansing, Michigan
}

\begin{abstract}
The construction of a computerized research system is described. Stimuli are presented to a pigeon on a color television monitor. Pecks at the television screen are detected by a network of multiplexed infrared emitters and detectors; the coordinates of the peck are transmitted to the host computer. Computer graphics allows the experimenter to simultaneously present a variety of forms and colors as stimuli. The system accommodates innovative research methodology in animal cognition, animal psychophysics, comparative psychology, and other research interests. With modification, the system can be used with other species, including humans.
\end{abstract}

The use of experimental chambers for investigating cognitive processes in animals has a long history in experimental psychology (Boakes, 1984). A renewed interest in animal cognition has led many investigators to employ the Skinner box. Unfortunately, the Skinner box was not designed for research in animal cognition, and, since its development, some technological advances have been made. Inline projectors permit presentation of up to 12 different stimuli, and carousel projectors provide for rear projection of colored slides on the response keys. However, when pigeons serve as subjects, the circumference of commercially available response keys typically limits the size of the stimuli to less than $2.54 \mathrm{~cm}$. Although the methods of programming experimental events and recording data have evolved from electromechanical circuits to transistor and then to computer control, the experimental chamber has remained essentially unchanged from the version described by Ferster and Skinner (1957).

We propose that a state-of-the-art chamber for use with animal subjects is obtained by replacing the response panel of Ferster and Skinner's (1957) chamber with a video monitor as the means of presenting stimuli to animal subjects. Computer-controlled graphics are commonly used in research on visual cognition with human subjects (Freeman, 1986; Pinker, 1984). Blough's $(1979,1982)$ research on form recognition by pigeons and Neiworth and Rilling's (1987) use of moving trajectories of rotating stimuli to study imagery in the same animal, demonstrate

The development of the research system and the research were supported by a faculty research grant to the first author. Mark Rilling's research on touch technology was supported by a grant from the Michigan State University Foundation and Grant BNS 8605524 from the National Science Foundation. Reprints can be obtained from R. Pisacreta, Department of Social Sciences, Ferris State College, Big Rapids, MI 49307, or from M. Rilling, Department of Psychology, Michigan State University, East Lansing, MI 48824. that good stimulus control can be obtained using a TV monitor.

Although Neiworth and Rilling (1987) obtained excellent stimulus control by mounting standard pecking keys in front of the TV monitor, keys restrict the location of the peck and block some portions of the pigeon's view of the video monitor. Therefore, we developed a system that employs an infrared "touch" technology to serve as a response detector.

Clauson, Izatt, and Shimp (1985) and Blough (1982, 1986) successfully detected the location of a pigeon's beak during a peck by measuring the interruption of an nfrared emitter-detector circuit. However, the number of response locations that could be detected was limited. However, the best commercial systems employ a SMART FRAME in which various operating and reporting modes can be specified with software under the control of the experimenter.

In this paper, we describe a research system that employs a Carroll Touch SMART FRAME infrared sensing system ${ }^{1}$ with ATARI computer products. The reader can use another computer and infrared system if the system provides at least two RS-232C serial ports. However, the software and initializing programs must be modified if other systems are employed (see Campbell, 1984, and Seyer, 1984, for a description of serial ports). As described, the system is designed for use with pigeons; however, it can be modified to accommodate other species (viz., crows, monkeys, apes, and human subjects).

\section{THE SYSTEM}

The top half of Figure 1 presents guidelines for the construction of the animal's environment. The dimensions of the outer enclosure (the upper left side of the figure) are designed to accommodate a 13-in. color television 

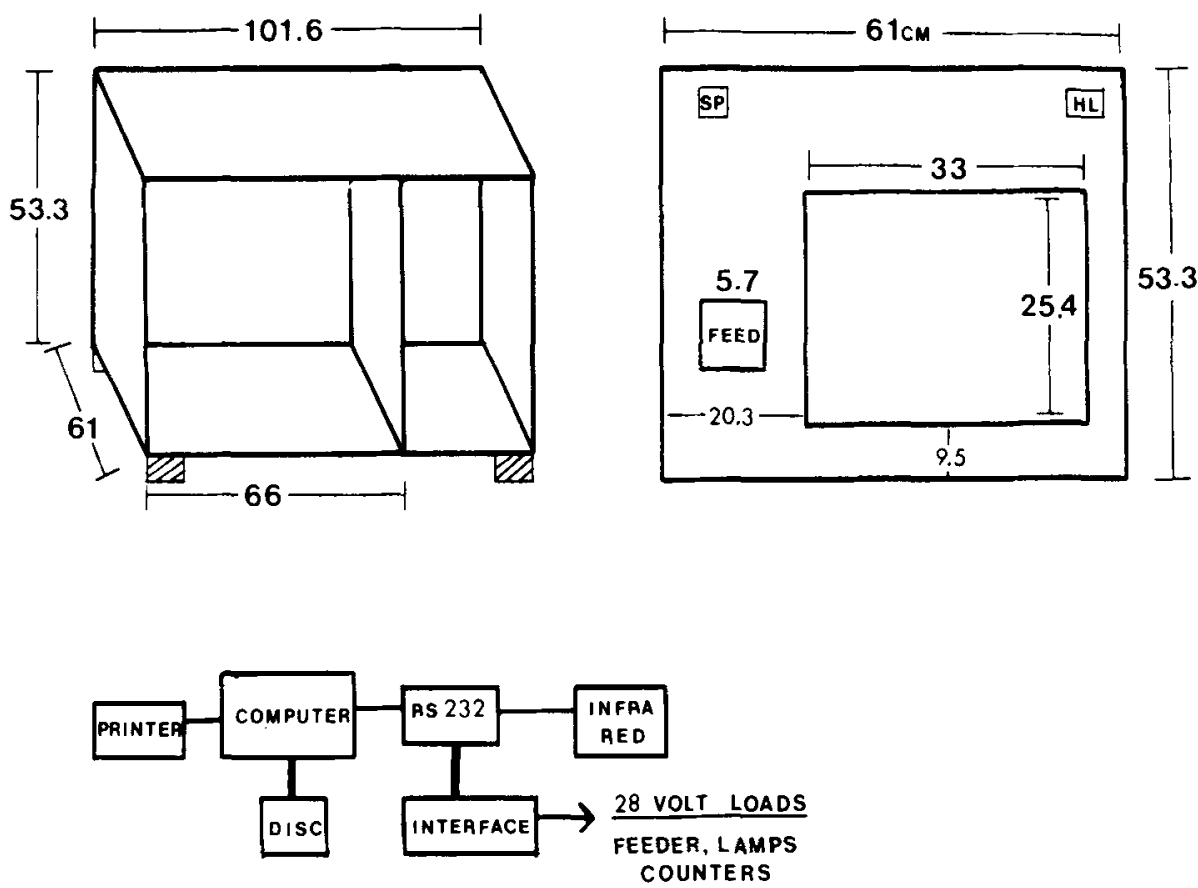

Figure 1. Recommended dimensions for constructing the outer enclosure and the response panel. The front door (not shown) should be hinged to allow easy access to the subject and TV monitor. A block diagram of the electronics is provided in the lower portion of the figure.

monitor and to provide ample space for heat dissipation. A ventilation fan is mounted on the pigeon's side (the right compartment) of the chamber. The wall facing the experimenter is hinged to provide easy access to the subject, feeder, TV, and cables. This hinged door is equipped with a peephole or one-way glass for the experimenter to directly observe the subjects. The aluminum response panel that the pigeon faces is depicted in the upper right corner of Figure 1. This panel and the walls and ceiling of the chamber should be painted flat white to reduce reflections. The heights of both the feeder aperture and the TV monitor are convenient for pigeons. The touch SMART FRAME is mounted in front of the TV, and both are recessed $1.25 \mathrm{~cm}$ behind the $33 \times 25.4 \mathrm{~cm}$ hole in the response panel. Suggested locations for the houselight (HL) and masking noise speaker (SP) are also provided.

Our system employs an AMDECK 500 color monitor with a typical convex screen. In order to minimize parallax, the infrared-emitting diodes (ILEDs) in the SMART FRAME are mounted in convex horizontal and vertical arcs to conform as closely as possible with the curvature of the monitor. The selection of a SMART FRAME must be made in conjunction with the curvature of the monitor selected by the experimenter. Upon request, the Carroll Touch company will provide information on monitor and SMART FRAME compatibility. If the monitor and SMART FRAME are purchased separately and the experimenter desires to place the SMART FRAME as closely as possible in front of the monitor, it is necessary to remove the original bezel, or plastic frame, from around the monitor. Replacing the original bezel with the infrared transparent bezel, within which the ILEDs are permanently mounted, provides a system with minimum parallax error.

The lower portion of Figure 1 provides a block diagram of the system. The ATARI system consists of the ATARI 130XE computer, 1050 disc drive, 1025 printer, and the Carroll Touch 13-in. SMART FRAME infrared sensing unit. The RS-232C component is the ATARI 850 interface, which features four independent serial RS-232C ports. The system will work with an ATARI 800XL or 520ST computer. The ATARI products were selected because they are versatile, reliable, and economical. The computer features $131 \mathrm{~K}$ of RAM, 16 graphics modes, 256-color capability, and four voice channels to provide sound. The graphics modes range from $20 \times 20$ to $192 \times 320$ screen locations, and eight different colors can be simultaneously present on the TV screen. The computer also has two joystick ports that can be wired to 10 push-button switches. The switches enable the researcher to introduce 10 different commands (e.g., cancel the session, print the data, skip to the last 10 trials) while the program is being executed. The computer, disc drive, printer, and RS-232C unit can be obtained for under $\$ 1,000$. The interface depicted in the figure will be discussed later.

The SMART FRAME requires a separate power supply that may be obtained from Carroll Touch or built by the investigator. The SMART FRAME requires $+5 \mathrm{~V} @$ $3 \mathrm{~A},+12$ V @ $0.2 \mathrm{~A}$, and $-12 \mathrm{~V} @ 0.2 \mathrm{~A}$. The SMART FRAME has an array of ILEDs and phototransistor detectors mounted on opposite sides of an optoframe in the $x$ and $y$ axes. The 13-in. frame uses a matrix of 48 ( $x$ axis) 
Table 1

Sample Touch Reports

\begin{tabular}{|c|}
\hline Report Received (in HEX) \\
\hline $\begin{array}{l}\text { Coordinate: }=============\mathrm{FE} X \mathrm{Y} \mathrm{FF} \\
\text { FE- start of report, } \mathrm{X} \text { - the mean of all X beams blocked, } \mathrm{Y} \text { - the } \\
\text { mean of all } \mathrm{Y} \text { beams blocked, FE- end of report. }\end{array}$ \\
\hline 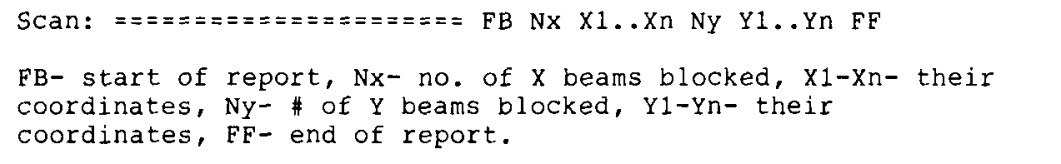 \\
\hline $\begin{array}{l}\text { Non-Contiguous styli: }======\mathrm{FC} \mathrm{T} F \mathrm{~F} \\
\text { FC-start of report, T-identifies as non-contiguous X-stylus, } \\
\text { Y-stylus, or both, FF- end of report. }\end{array}$ \\
\hline $\begin{array}{l}\text { No reports available: }======\mathrm{F} 5 \mathrm{FF} \\
\text { F5- start of report, } \mathrm{FF} \text { - end of report, no blocked beams. }\end{array}$ \\
\hline $\begin{array}{l}\text { The researcher can select via software from a variety of } \\
\text { operating modes: } \\
\text { Continuous mode reports coordinates as long as a stylus is in } \\
\text { the touch active area, } \\
\text { Enter point mode reports only the coordinates where the stylus } \\
\text { entered the touch active area, } \\
\text { Tracking mode reports coordinates only as long as the stylus is } \\
\text { Exoving, } \frac{\text { Exit point mode reports coordinates only when the stylus has }}{\text { left the touch active area. }} \\
\text { several self test reports are also available including: Failed } \\
\text { beam locations, Rom status, and diagnostics. }\end{array}$ \\
\hline
\end{tabular}

$\times 32$ ( $y$ axis) detectors. The emitter/detector pairs are sequentially scanned by a sequence of pulses that creates an invisible lattice of infrared light beams within the frame. The entire lattice is scanned 20 times per second. The "touch active" zone is $27.5 \times 19.3 \mathrm{~cm}$, with no dead spots. Interrupting the beams with a stylus, a finger, or a pigeon's beak obstructs the light beams from certain ILEDs. Serially measuring the outputs of the phototransistors provides the $x$ and $y$ coordinates of the location of the stylus, which serve as the response input to the computer. The minimum stylus size is $8.8 \mathrm{~mm}$.

The SMART FRAME can be software programmed to provide several different kinds of reports. Table 1 presents examples of some of the reports available. The coordinate reports range in $x$ from 0 to 94 and in $y$ from 0 to 62 , for a total matrix of 5,985 locations $(95 \times 63)$. The SMART FRAME is cabled to Port 1 of the RS-232C ATARI 850 interface. For maximum hardware and software control, the RS-232C and SMART FRAME Data Terminal Ready (DTR), Data Set Ready (DSR), Clear to Send (CTS), and Request to Send (RTS) lines should be used, as well as the Receive Data (RD), Transmit Data (TD), and signal ground wires. Reports are transmitted as 8-bit words with software choice 1 or 2 stop bits, and odd or even parity. BAUD rate ranges from 300 to 19,200 , also software programmable. Additionally, the SMART FRAME has several self-test modes, and will test its own ROMs, report locations of failed or weak ILEDs and detectors, and report on the status of its communication with the computer. The ATARI 130XE computer also has self-test modes that indicate failed ROMS, faulty RAM locations, and faulty keyboard keys.

For research purposes, one of the advantages of infrared scanning is that the view of the TV screen remains unobstructed. With infrared scanning, it is not necessary to actually touch the TV screen. Also, since the beams are invisible, infrared systems do not distort the images on the TV screen. Ambient light will not affect the system, which will operate at temperatures between $0^{\circ} \mathrm{C}$ and $50^{\circ} \mathrm{C}$.

With the hardware for the SMART FRAME in place, the next step is software development to handle commu- 
Table 2

Initializing and Report Request Program

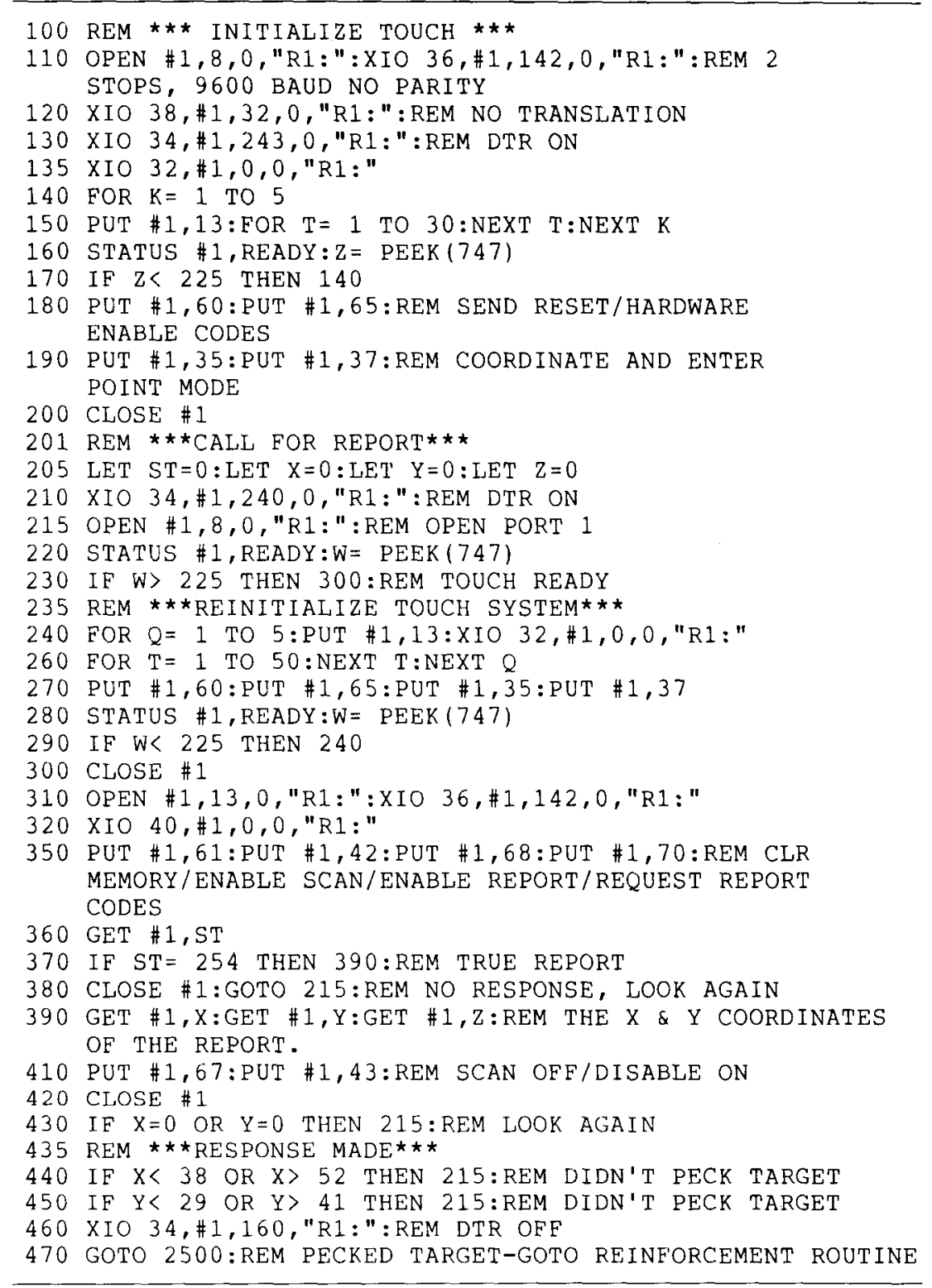

nications between the host computer and the SMART FRAME. Programs are necessary to (1) initialize the SMART FRAME by commands from the host computer at the beginning of a session, and (2) send reports of pecks from the SMART FRAME to the host computer. Table 2 shows the initializing routine necessary to boot up the SMART FRAME (lines 100-200) and the method for requesting a report from the SMART FRAME. The SMART FRAME is called by turning the DTR line on, checking the CTS line, and then sending the appropriate codes. Lines 220-300 verify that the SMART FRAME is ready and reboot it if necessary. Lines $310-430$ continuously call for a report until a response is made. Lines 440-500 designate a response to the middle of the TV monitor as the correct response. The lag time between consecutive reports can be shortened by writing the program as a machine language routine and addressing it via the USR function. For users with an IBM PC or compatible computer, a well-documented programming example in BASIC is available in Carroll Touch (1986).

Two TV monitors are used. The experimenter's monitor is always on. The video and audio signals to the bird's monitor are wired through a relay. During experimental sessions, the experimenter's monitor displays the same stimuli that are presented to the bird and the computer's audio signal is sent to the subject's monitor. Between sessions, the bird's monitor is off (i.e., a dark screen with no audio). The experimenter's monitor can then be used to display data entered by the keyboard, such as the date, bird number, session number, and so forth. These visual stimuli are not presented to the pigeon.

A second interface is necessary so that the computer can control other experimental devices, such as the grain feeder, houselight, cumulative recorders, and counters. 

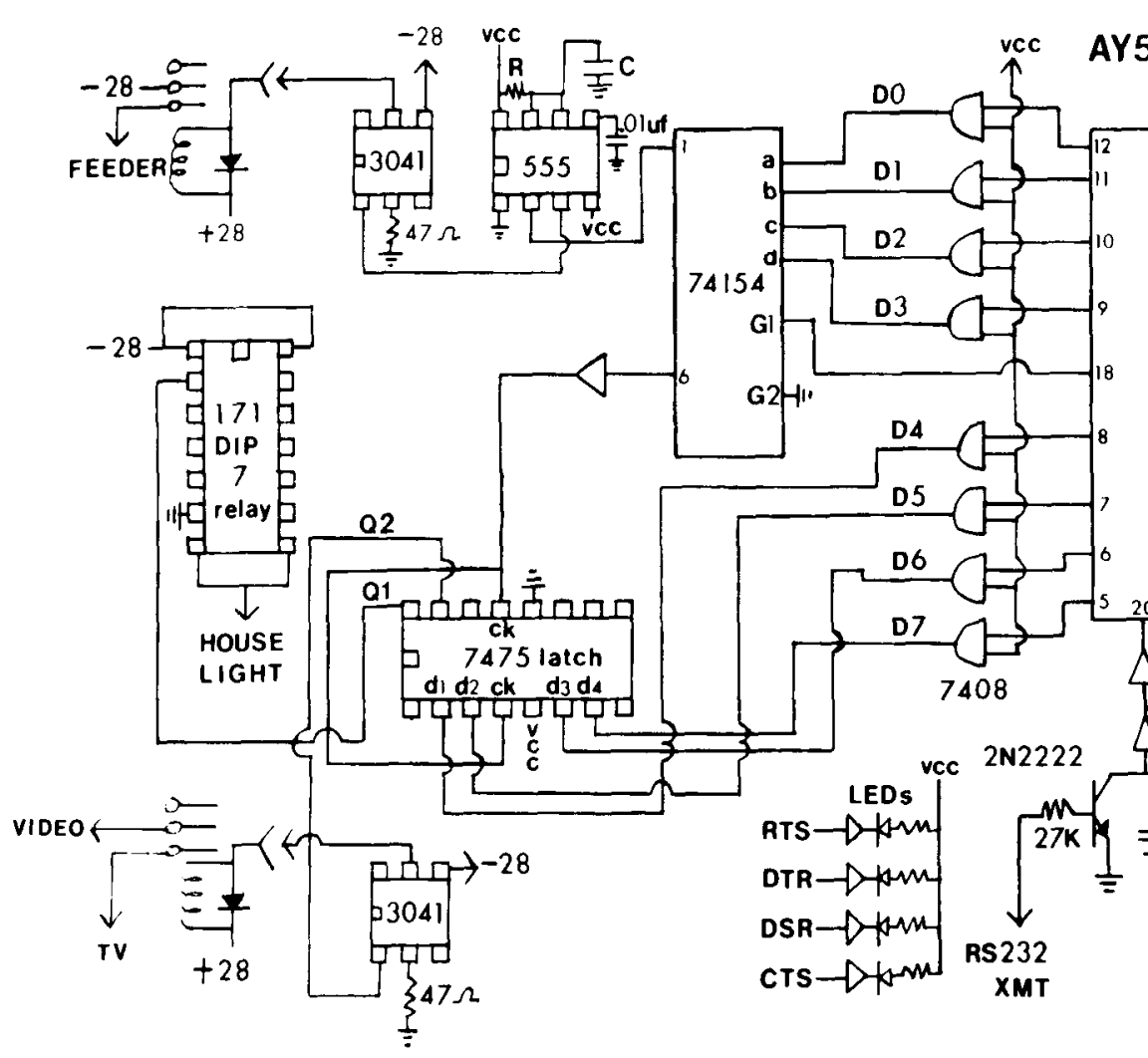

Figure 2. The schematic of the interface.

Several commercial units are available for that purpose. ${ }^{3}$ We present an economical alternative that can operate 18 different 28-V devices (see Figure 2). A UART, or universal asynchronous receiver-transmitter, is an integrated circuit (IC) that is frequently employed for serial data transmission between different devices. Our interface employs the AY51013 UART IC. The XMT (Transmit) and DTR (Data Terminal Ready) lines from Port 2 of the ATARI 850 interface control the UART via the 2N2222 NPN buffering transistors, and inverters connected to pins 20 and 21 , respectively. The 555 connected to the clock pins 17 and 40 is wired as a multivibrator calibrated at $4800 \mathrm{~Hz}$. This clock speed sets the BAUD rate at 300 . Pins 4, 16, 23, and 34-39 are wired to enable the UART to receive 8-bit words with two stops and to transfer the words to the eight parallel output lines 5-12. The two AND gate ICs (SN7408) connected to these lines can drive up to 10 loads.

Three types of 28-V loads are typical. Counters require a 150 -msec pulse to operate. Grain feeders are usually operated for $3 \mathrm{sec}$ and require $3 \mathrm{~A}$ of current. Houselights must remain on or off for minutes or hours. The SN74154, 4-16 decoder IC, is used to address the different $28-\mathrm{V}$ devices. The schematic demonstrates our method of operating the $28-\mathrm{V}$ grain feeder. The computer program puts the DTR line in the "high" state and sends the XMT line the HEX number 1 from the computer. After a short delay, the DTR line is put back in the "low" off state. These events make Line D0 present a "high" to input line a of the SN74154. Lines D1, D2, and D3 present a "low" to inputs $b, c$, and $d$, respectively. When these signals are stable, pin 18 of the UART enables the SN74154 IC via its G1 connection. The SN74154 responds by making output line 1 go low for a moment. This high to low pulse triggers a $555 \mathrm{IC}$ wired as a one-shot. Its capacitor (C) and resistor (R) values were selected to enable the IC to remain on for $3 \mathrm{sec}$. The output of the 555 operates an optoisolator (ECG3041), which in turn provides $28 \mathrm{~V}$ to operate a relay. The heavy-duty relay contacts are used to operate the grain feeder. Low current loads, less than $100 \mathrm{~mA}$, can operate directly from the optoisolator. The reader can also drive $\mathrm{SN} 7490$ decade counters and SN7447 readout driver ICs directly from one of the SN74154 outputs. This will enable the computer to control digital readouts.

Wiring data lines D4-D7 to a SN7475 latch IC enables us to leave up to four devices constantly on. When the computer transmits the HEX number 16, data lines D1, D2, and D4 go "high" while the other data lines remain "low." Output line 6 of the SN74154 clocks the latch IC. The "high" on input d1 appears at the output Q1 and remains there until the latch IC is again addressed. The Q1 output drives a 171 DIP 7, an IC relay that in turn operates the houselight. Similarly, sending the HEX number 26 will turn off the houselight and turn on output Q2 instead. This output is used to drive an optoisolator/relay circuit that controls the video signal to the bird's TV. A second set of contacts on this relay (not shown) switches the computer's audio output from the experimenter's monitor, which is connected to the normally closed relay contacts, to the subject's monitor (via the normally open contacts) when the relay is on. Transmitting the HEX 
Table 3

Parts List

\begin{tabular}{cll}
\hline Quantity & Part No. & \multicolumn{1}{c}{ Description } \\
\hline 1 & AY51013 & UART \\
$2^{*}$ & SN555 & Timer \\
2 & SN7408 & AND gate \\
$2^{*}$ & ECG3041 & Optoisolator \\
1 & SN7475 & 4-bit latch \\
2 & SN7404 & Hex inverter \\
1 & SN74154 & 4-16 decoder \\
$1^{*}$ & 171 Dip 7 & Solid-state·relay \\
2 & $2 N 2222$ & Transistors \\
8 & & LEDS \\
1 & & 25K 10-turn pot \\
\hline
\end{tabular}

Note-These components can be obtained from JAMESCO ELECTRONICS, 1355 Shoreway Rd., Belmont, CA 94002 . The resistors are all $1 / 4 \mathrm{~W}$. Capacitors are all rated at $20 \mathrm{~V}$. *The minimum number necessary. More may be required depending on the number of devices that the researcher wishes to control.

numbers 36 or 6 will leave both outputs on or off, respectively. Light-emitting diodes (LEDs) are employed for the purpose of providing the researcher with feedback. The RTS, DTR, DSR, and CTS LEDs will all be on when the computer and SMART FRAME are communicating; the PARITY, FRAME, and OVER RUN LEDs alert the investigator to any UART problem; and the DAV LED flashes whenever a word has been successfully received. (A parts list and supplier are presented in Table 3.)

The ICs are mounted in a steel box. The $28-\mathrm{V}$ relays are wired in a separate cabinet to prevent relay contact arcing from disturbing the ICs. A well-filtered power supply should be used and its ground line must be tied to one of the ATARI 850 ground lines. Additional interfacing circuits are described by Rony, Larsen, and Titus (1977). For example, the D4-D7 lines from the UART could be connected to the a-d input lines of each of 15 SN74154 ICs. Their enable pins (G1 and G2) can be wired to separate output lines of another SN74154 wired to data lines D0-D3. This scheme enables the researcher to control about 225 different devices.

Table 4 shows the BASIC program used to address the interface. Lines 500-520 establish the BAUD rate, parity, and number of stops. The command to the interface is called as a subroutine. The subroutine is called after $x$ is made equal to the decimal equivalent of the HEX number the user wishes to send to the interface (line 530).

The SMART FRAME has an average life expectancy of $96,000 \mathrm{~h}$ without component failure (e.g., IR LED failure, ROM malfunction). The interface has been operating for 2 years without failure.

\section{THE EXPERIMENT}

A number of researchers have investigated spatial problem solving in nonhumans (e.g., Hanley \& Levine, 1983; Levine, Jankovic, \& Palij, 1982). We wanted to see if pigeons could reliably solve simple straight maze visual problems.

\section{Method}

Subjects. Seven White Carneaux pigeons, maintained at $80 \%( \pm 15 \mathrm{~g})$ of free-feeding weights, were used.

Procedure and Results. After preliminary training, four different maze problems were presented during daily experimental sessions. Two are represented at the top of Panel 1 of Figure 3. The horizontal maze in the upper left corner of the panel was a $25.4 \times 11.43 \mathrm{~cm}$ whitebordered rectangle presented on a dark background. A white goal was present at the right end of the maze. A red- and a yellow-colored block were presented in the center fo the maze. These $2.54 \times 1.59 \mathrm{~cm}$ blocks were located $20.32 \mathrm{~cm}$ from the goal. A peck to the red block moved both blocks $10.16 \mathrm{~cm}$ toward the goal. A peck to the yellow block moved both blocks $10.16 \mathrm{~cm}$ away from the goal. Two correct pecks moved the blocks into the goal. A third peck to the red block produced a reinforcer and the next trial. Two pecks to the yellow block moved the blocks to the left end of the maze. Five pecks to the red block were necessary to move the blocks back toward the goal. This problem was presented during $25 \%$ of the session trials. During another $25 \%$ of the trials, the goal was presented in the left end of the maze. During these trials, pecks to the yellow square were correct.

Two vertical maze problems were presented during the remainder of the trials. One of these is depicted at the right side of Panel 1, Figure 3. A peck to the blue block moved both blocks upward toward the goal. During $25 \%$ of the trials, the goal was presented at the bottom of the

Table 4

Initializing and Addressing the Interface Program

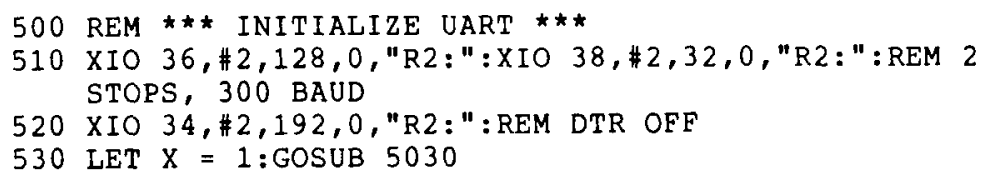




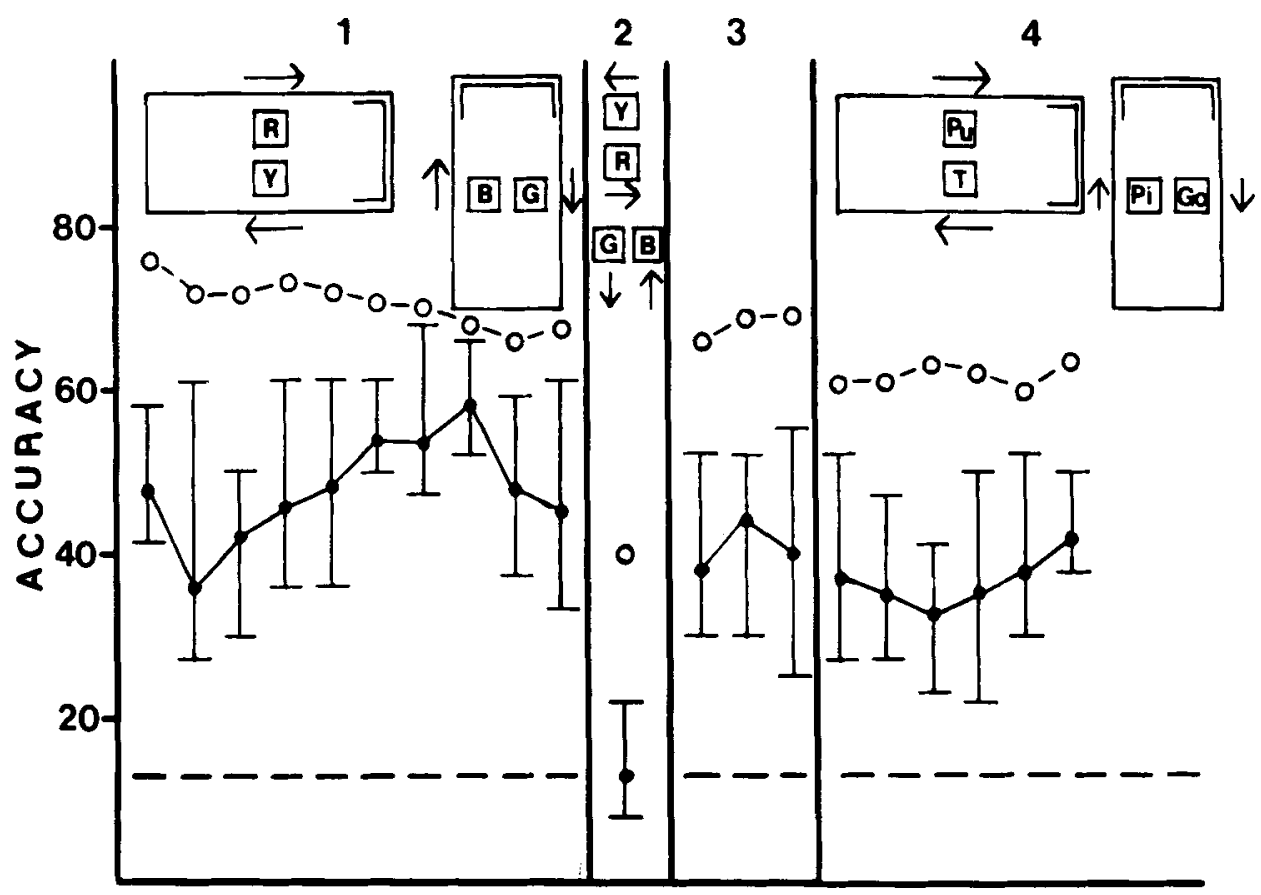

\section{SESSIONS}

Figure 3. Data generated during the visual maze learning experiment. The filled circles represent the percentage of reinforced trials on which the birds made no errors (group data). The range of performance is also noted. Unfilled circles represent the percentage of correct responses produced during the session. Panel 1 shows the last 10 sessions of preliminary training. Two of the four mazes employed are represented in the top of the panel. During the other trials, the goal was presented in the opposite end of the mazes. The color blocks were R(ed), Y(ellow), B(lue), and G(reen). Arrows indicate the direction the blocks moved if they were pecked. The top of Panel 4 indicates that novel color blocks were introduced. They were Pu(rple), T(urquoise), Pi(nk), and Go(ld).

maze. Pecks to the green block moved both blocks down into the goal. The birds were trained during $\mathbf{4 0}$ daily sessions. Each session ended after 36 reinforcers were produced (the four mazes presented nine times each).

Panel 1 of Figure 3 presents data generated during the last 10 sessions of training. The filled circles (group data) represent the percentage of the reinforced trials that produced no errors. That is, the first peck to a block was correct, and the bird continued to shuttle across the response panel pecking this block until it was in the goal. A minimum of three correct pecks per trial was required. Chance performance (the dotted line) was $12.5 \%$. The range in performance was primarily due to some birds' reliably performing better or poorer than the average birds.

The unfilled circles represent the ratio of correct responses to total responses emitted during a session (i.e., the percentage of correct responses). About $75 \%$ of the birds' pecks were correct. This measure also indicates that when the birds made an error, they quickly switched to the other (correct) block.

Did the color of the blocks or their positions control responding? That is, did the birds learn to associate a red block, or the upper block, with movement to the right? During one session, presented in Panel 2 of Figure 3, the positions of the blocks in the mazes were reversed. The accuracy levels of the birds dropped to chance, and less than half of their responses were to the correct blocks. One of the birds made 182 errors within the first three trials and stopped responding.

During the three sessions presented in Panel 3 of Figure 3, the original training conditions were reinstated. Each bird recovered its original performance level. Finally, we changed the colors of the blocks but left their direction of movement unchanged. Panel 4 indicates that the red and yellow blocks were replaced with purple and turquoise blocks, respectively. Pink and gold blocks replaced the green and blue blocks. Panel 4 shows that the overall accuracy performance of the birds was maintained under these conditions. The data suggest that the birds had learned to associate particular block locations and not colors with direction of movement.

\section{CONCLUSION}

The use of computer-controlled graphics systems achieves one of our goals of narrowing the gap between the technology used with human and animal subjects, by providing animal researchers with versatile equipment. The cost of a computer-controlled video monitor with a SMART FRAME (about $\$ 2,000$ ) is within the budget of most laboratories and is comparable to the cost of a tradi- 
tional experimental chamber equipped with keys and a slide projector. The increase in response locations and the potential of computer graphics fully justify the potential of this equipment as a research tool. The touch system can be employed with any computer system equipped with a RS-232C port and a standard video monitor. The system can be modified for use with other species (e.g., crows, monkeys, and apes). If the TV monitor and SMART FRAME are turned $90^{\circ}$, both human and nonhuman subjects can be tested under comparable conditions. By presenting the same stimuli to different species, variations in apparatus can be greatly reduced as a possible source of differences in performance among species. This system can be used with developmentally disabled, brain damaged, or other populations of people who are unable to use a conventional keyboard. Much of the research with normal human subjects and computers requires that the subjects divide their attention between the video screen and the keyboard on which they enter responses. The system will keep the subject's undivided attention on the monitor. Additionally, touch technology is engineered as a modular technology, so a touch system can be retained as improved computer graphics or monitors with higher resolution are added to upgrade the system. Therefore, the system can be a useful tool for experimental and applied psychologists engaged in a wide variety of research pursuits.

\section{REFERENCES}

Boakes, R. (1984). From Darwin to behaviorism: Psychology and the mind of animals. Cambridge, England: Cambridge University Press.

BLough, D. S. (1979). Effects of the number and form of stimuli on visual search in the pigeon. Joumal of Experimental Psychology: Animal Behavior Processes, 5, 211-233.

Blough, D. S. (1982). Pigeon perception of letters of the alphabet. Science, 218, 397-398.
BLough, D. S. (1986). Odd-item search by pigeons: Method, instrumentation, and use. Behavior Research Methods, Instruments, \& Computers, 18, 413-419.

CAMPBELl, J. (1984). The RS-232 solution. Berkeley, CA: Sybex.

Carroll Touch (1986). Smar-frame TM programmers guide. Round Rock, TX: Author.

Clauson, H. D., Izatt, E. J., \& Shimp, C. P. (1985). An infrared system for the detection of a pigeon's pecks at alphanumeric characters on a TV screen: The dependency of letter detection on the predictability on one letter by another. Journal of the Experimental Analysis of Behavior, 43, 257-264.

FERSTER, C. B., \& SKINNER, B. F. (1957). Schedules of reinforcement. New York: Appleton-Century-Crofts.

Freeman, H. (1986). Computer graphics. In K. R. Boff, L. Kaufman, \& J. P. Thomas (Eds.), Handbook of perception and human performance (Vol. 1, pp. 1-42). New York: Wiley-Interscience.

HanLEy, G. L., Levine, M. (1983). Spatial problem solving: The integration of independently leamed cognitive maps. Memory \& Cognition, 12, 415-422.

Levine, M., Jankovic, I. N., \& PaluJ, M. (1982). Principles of spatial problem solving. Journal of Experimental Psychology, 111, 157-175.

Neiworth, J. J., \& Rilling, M. E. (1987). A method for studying imagery in animals. Journal of Experimental Psychology: Animal Behavior Processes, 13, 203-214.

Pinker, S. (1984). Visual cognition: An introduction. Cognition, 18, $1-63$.

Rony, P. R., Larsen, D. G., \& Titus, J. A. (1977). The 8080A bugbook: Microcomputer interfacing and programming. Indianapolis, IN: Sams.

SEYER, M. D. (1984). RS-232C made easy. Englewood Cliffs, NJ: Prentice-Hall.

\section{NOTES}

1. Carroll Touch Technology, P. O. Box 1309, Round Rock, TX 78680 .

2. Black Box Corporation, Mayview Rd. at Park Dr., Box 12800 , Pittsburgh, PA 15241. MED Associates Inc., Box 47, East Fairfield, VT 05448.

(Manuscript received February 9, 1987; revision accepted for publication June 17, 1987.) 